\title{
Clinical utility of vandetanib in the treatment of patients with advanced medullary thyroid cancer
}

This article was published in the following Dove Press journal:

OncoTargets and Therapy

8 December 201I

Number of times this article has been viewed

\author{
Hari Deshpande ${ }^{1,3}$ \\ Vicky Marler ${ }^{3}$ \\ Julie Ann Sosa ${ }^{2,3}$ \\ 'Department of Medicine, \\ ${ }^{2}$ Department of Surgery, Yale \\ University School of Medicine, ${ }^{3}$ Yale \\ Cancer Center, New Haven, CT, USA
}

Correspondence: Hari A Deshpande 333 Cedar Street, FMP 124, New Haven, CT 06520, USA

$\mathrm{Tel}+\mathrm{I} 2037375312$

Fax + I 2037853788

Email hari.deshpande@yale.edu

\begin{abstract}
Vandetanib (ZD6474) became the first systemic agent to be approved for the treatment of metastatic or locally advanced medullary thyroid cancer. It was a proof of principle, because it is an orally bioavailable medication that targets the growth factors felt to be important in the pathogenesis of this disease, ie, the rearranged during transfection proto-oncogene and vascular endothelial growth factor receptor. It was tested initially in two Phase II studies at doses of $100 \mathrm{mg}$ and $300 \mathrm{mg}$ daily. Although activity was seen at both doses, the higher dose was chosen for a randomized, placebo-controlled Phase II study. This trial, which accrued more than 300 patients, showed a statistically significant benefit for the group taking vandetanib compared with those taking placebo medication. Progression-free survival for the vandetanib arm has not been reached, compared with 19 months for the placebo arm. The main toxicity appears to be diarrhea, although some patients experienced significant side effects, including torsades de pointes and sudden cardiac death. Therefore, it is now necessary for practitioners to enroll in a Risk Evaluation Mitigation Strategy before being allowed to prescribe this medication, to reduce the risk of serious side effects occurring.
\end{abstract}

Keywords: ZD6474, medullary thyroid cancer, vandetanib

\section{Introduction}

Medullary thyroid cancer (MTC) accounts for 3\%-12\% of thyroid cancer cases in most series. It arises from the C (parafollicular) cells, and does not occur because of radiation exposure, which has been identified as a risk factor for the development of papillary thyroid cancer. ${ }^{1}$ The disease was first described in the $1950 \mathrm{~s}^{2}$ Most cases are still sporadic $(60 \%-70 \%)$, but the familial syndrome and association with other disorders, including pheochromocytoma and primary hyperparathyroidism, ${ }^{3}$ have been extensively researched over the last 50 years. Multiple hereditary forms of this disease have since been described, including familial MTC and the multiple endocrine neoplasia syndromes (MEN 2A and MEN 2B). ${ }^{1,4-6}$ MEN 2A accounts for $60 \%$ of the hereditary forms, MEN 2B 5\%, and FMTC 35\%. ${ }^{7}$

Survival is dependent on the stage of MTC at diagnosis. This is one of the most significant prognostic factors on multivariate analysis. Historically, survival for patients with MTC requiring systemic therapy was 6-22 months. ${ }^{8}$ A review of more than 1200 cases demonstrated a mean survival time after diagnosis of MTC of 8.6 (range 0-29.6) years. Patients with tumors confined to the thyroid gland had a 10 -year survival rate of $95.6 \%$, whereas patients with regional stage disease had an overall survival rate of $75.5 \%$. Patients with distant metastases at diagnosis had a poor prognosis, with only $40 \%$ surviving 10 years and an overall survival of around 36 months. ${ }^{9}$ 
Chemotherapeutic agents, such as doxorubicin and cisplatin, have been used in the treatment of unresectable MTC with limited success, considerable toxicity, and responses lasting only 9-22 months. ${ }^{10}$

Recent advances in drug development have led to the synthesis of many new targeted agents that are inhibitors of specific growth factors or cell signaling pathways involved in the pathogenesis of MTC. ${ }^{11}$

Mutations in specific regions of the rearranged during transfection (RET) proto-oncogene have been described in patients with both familial and sporadic forms of MTC. RET encodes for a transmembrane growth factor receptor that is involved in cell signaling and ultimately the uncontrolled growth of malignant MTC cells. Therefore, RET represents an obvious target for specific drugs to treat unresectable forms of this disease.

Many cancers rely on angiogenesis or the formation of new blood vessels to enable growth of the primary tumor and metastasis to distant sites. Angiogenesis appears to be controlled by a variety of proteins, including vascular endothelial growth factor (VEGF) and its specific receptor (VEGFR) on the cell surface. Because these are often overexpressed in thyroid cancers, antiangiogenesis agents have been developed as targeted treatments. Vandetanib (ZD6474, Caprelsa ${ }^{\mathrm{TM}}$, AstraZeneca) targets both the RET proto-oncogene and the VEGF receptor, and is described in detail in this review.

\section{Targets of vandetanib: RET and VEGF \\ RET proto-oncogene}

RET was first discovered in patients with MEN syndromes, ${ }^{12}$ although it was not until 1985 that a new human transforming gene was detected by transfection of NIH 3T3 cells with a lymphoma DNA. ${ }^{13}$ Subsequent work pinpointed mutations on chromosome 10 , followed by the identification of germline mutations in the RET proto-oncogene, located at 10q11.2, in patients with MEN 2A, MEN 2B, and familial MTC. ${ }^{6}$

RET is now felt to be one of a number of receptor tyrosine kinases which are present on cancer cells. These glycoproteins, including RET, receive extracellular signals for processes as diverse as cell growth, differentiation, survival, and programmed cell death (Figure 1). In response to binding of extracellular ligands, receptor tyrosine kinases generally form homodimers or heterodimers. On dimerization, autophosphorylation occurs, followed by intracellular signal transduction through effectors that recognize and interact with the phosphorylated form of the receptor tyrosine kinase.

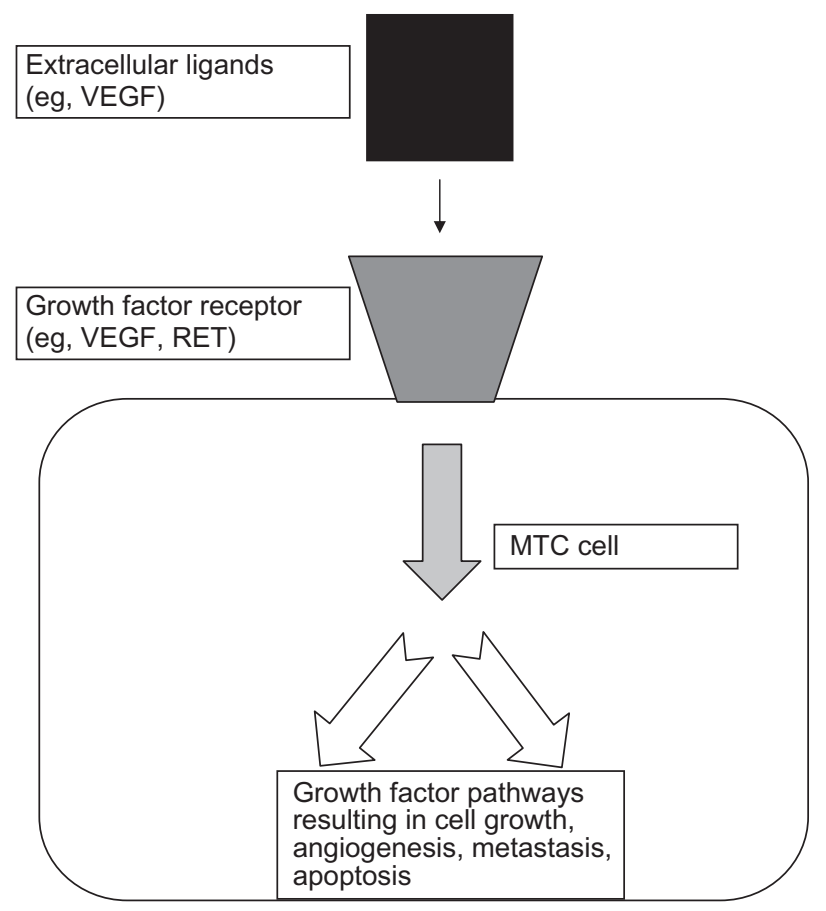

Figure I Interaction of extracellular ligands with growth factor receptors on medullary thyroid cancer cells.

Abbreviations: MTC, medullary thyroid cancer; VEGF, vascular endothelial growth factor; RET, rearranged during transfection.

Although the downstream signaling pathways activated by these steps may be shared by different receptors, the ligand-receptor interaction itself is very specific. However, in some cases, high-affinity ligand-receptor tyrosine kinase interactions can be modulated by the presence of other, low-affinity, nonsignaling accessory molecules at the cell surface. ${ }^{14}$

\section{VEGF receptor}

The VEGFR pathway is also important in the pathogenesis of MTC. ${ }^{15}$ Three transmembrane receptors mediate the angiogenic and lymphogenic effects of VEGF, ie, VEGFR-1, VEGFR-2, and VEGFR-3. Of these, VEGFR-2 is believed to play the primary role in endothelial cell proliferation, migration, survival, and induction of vascular permeability characteristic of neovascularization required for tumor growth and metastasis. VEGF proteins secreted by the tumor cell act as ligands for the VEGFR, and a complex feedback loop is involved in the stimulation of angiogenesis (Figure 2). ${ }^{16}$

\section{Description of vandetanib}

Vandetanib (N-[4-bromo-2-fluorophenyl]-6-methoxy-7[(1-methylpiperidin-4-yl) methoxy] quinazolin-4-amine) is an oral anilinquinazoline compound with a molecular weight 


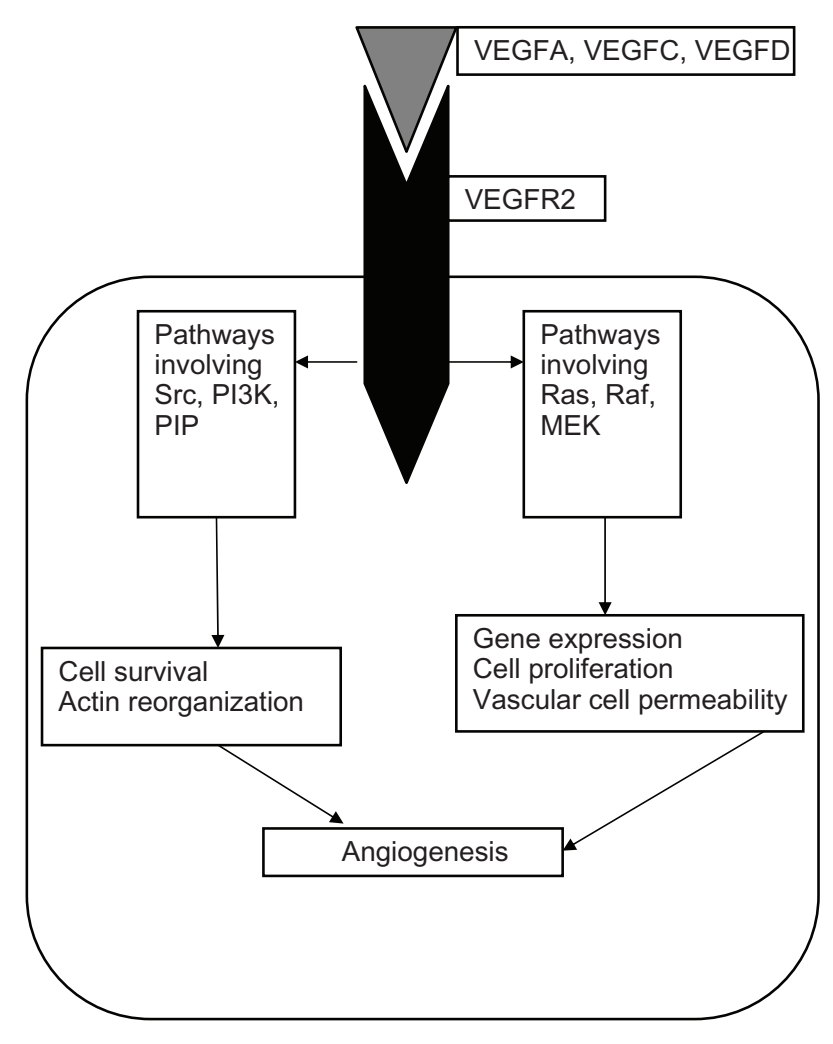

Figure 2 Interaction of ligands with vascular endothelial growth factor receptor. Abbreviations: VEGF, vascular endothelial growth factor; VEGFR, vascular endothelial growth factor receptor; RET, rearranged during transfection; PI3K, phosphoinositide 3-kinase; MEK, mitogen-activated protein kinase kinase; PIP, phospholipase inhibitor A2 from python.

of $475 \mathrm{Da}$. It competes with ATP binding in the catalytic domain of several tyrosine kinases. Recombinant enzyme assays have shown it to be a potent inhibitor of VEGFR-2 (50\% inhibitory concentration $\left.\left[\mathrm{IC}_{50}\right] 40 \mathrm{nM}\right)$, with additional activity against VEGFR-3 ( $\left.\mathrm{IC}_{50} 110 \mathrm{nM}\right)$, epidermal growth factor receptor $\left(\mathrm{IC}_{50} 500 \mathrm{nM}\right)$, and $\mathrm{RET}\left(\mathrm{IC}_{50} 130 \mathrm{nM}\right)$ kinases. Further studies on human umbilical vein endothelial cells have found vandetanib to be a potent inhibitor of proliferation of VEGFR-stimulated cells $\left(\mathrm{IC}_{50} 60 \mathrm{nM}\right)$ with higher doses necessary for epidermal growth factor receptorstimulated human umbilical vein endothelial cell proliferation $\left(\mathrm{IC}_{50} 170 \mathrm{nM}\right)$. Vandetanib showed excellent selectivity for these kinases compared with related receptor tyrosine kinases, such as platelet-derived growth factor receptor- $\beta$ and c-kit. ${ }^{17-19}$ This activity profile made it an attractive choice as a treatment for patients with unresectable MTC.

\section{Clinical studies involving vandetanib Phase I studies}

Phase I studies helped to establish the recommended dose of vandetanib. The first 77 patients were enrolled in the US and Australia. Adult patients with malignant solid tumors who were refractory to standard treatments or for whom no standard treatment existed were treated with a single oral vandetanib dose ranging from $50 \mathrm{mg}$ to $600 \mathrm{mg}$, followed by a 7 -day observation period (cycle 0 ). At the end of this period, they received once-daily treatment at the same dose level as cycle 0 for 28 days, and continued to receive further 28-day cycles until evidence of progression or dose-limiting toxicity. Seventy-six patients had at least one adverse event, most occurring for the first time during the initial 28-day treatment period. The most common drug-related adverse events were diarrhea $(n=29)$, rash $(n=26)$, nausea $(n=15)$, hypertension $(n=14)$, fatigue $(n=14)$, anorexia $(n=10)$, acneiform rash $(\mathrm{n}=9)$, and maculopapular rash $(\mathrm{n}=8)$. Drug-related adverse events that led to treatment discontinuation were congestive heart failure, follicular rash, folliculitis, and prolonged QT interval (all $\mathrm{n}=1$ ).

There were 43 dose-limiting toxicities reported, 27 of which occurred during the dose-escalation phase and 16 during the cohort expansion phase. Most of the 14 doselimiting toxicities reported within the first 35 days of the study (cycles 0 and 1) were at the $500 \mathrm{mg}$ and $600 \mathrm{mg}$ doses; three of eight patients at each dose experienced four and seven dose-limiting toxicities, respectively. Asymptomatic QTc prolongation was seen at the $500 \mathrm{mg}$ and $600 \mathrm{mg}$ dose levels; consequently, $300 \mathrm{mg}$ was the highest dose used during the cohort expansion phase of the study. Seven patients experienced QTc prolongation, although all occurrences were asymptomatic $(\mathrm{n}=1$ in the $100 \mathrm{mg}, 300 \mathrm{mg}$, and $600 \mathrm{mg}$ groups, and $\mathrm{n}=2$ in the $200 \mathrm{mg}$ and $500 \mathrm{mg}$ groups). Pharmacokinetic studies in this trial showed vandetanib to be extensively distributed, with a half-life of approximately 120 hours and a minimum of 28 days of continuous oral dosing required to achieve steady-state plasma concentrations. ${ }^{20}$ The second Phase I study was conducted in Japan, and enrolled 18 patients. ${ }^{21}$ Again, $300 \mathrm{mg}$ daily was determined to be the recommended dose, with a similar toxicity profile and pharmacokinetic findings.

\section{Studies involving vandetanib and MTC}

\section{Single-arm Phase II studies}

Germline mutations of RET cause the hereditary forms of MTC. Because RET is one of the main targets of vandetanib, two single-arm Phase II clinical trials were developed to evaluate the clinical utility of this agent in hereditary MTC (see Table 1). The first of these studies enrolled patients with unresectable, locally advanced, or metastatic MTC with a confirmed clinical diagnosis of MEN 2A, MEN 2B, or familial MTC and a germline RET mutation. They were 
Table I Studies evaluating the use of vandetanib in medullary thyroid cancer

\begin{tabular}{lllll}
\hline Study phase & Initial vandetanib dose & $\begin{array}{l}\text { Percentage with partial } \\
\text { response or better }\end{array}$ & Progression-free survival & Reference \\
\hline II & $300 \mathrm{mg}$ & 20 & 10.2 months & 22 \\
II & $100 \mathrm{mg}$ & 16 & Not reported & 23 \\
Randomized II/III & $300 \mathrm{mg}$ & 45 & Not reached & 24 \\
\hline
\end{tabular}

treated at an initial dose of $300 \mathrm{mg}$ daily. Inclusion criteria for this study included at least one measurable lesion according to Response Evaluation Criteria in Solid Tumors (RECIST) guidelines, World Health Organization performance status $0-2$, and adequate cardiac, hematopoietic, hepatic, and renal function. This was an open-label Phase II study conducted at seven centers worldwide, and patients received vandetanib at a daily dose of $300 \mathrm{mg}$ until progression of disease, withdrawal of consent, or unacceptable toxicity. The primary endpoint was objective response by RECIST, and secondary endpoints included duration of response, disease control, progressionfree survival, safety, and tolerability, as well as changes in serum levels of calcitonin and the glycoprotein carcinoembryonic antigen, which are both secreted by MTC cells. Thirty patients were enrolled from November 2004 to August 2006, and at the time of data cutoff(February 22, 2008), 17 patients were still continuing on treatment. Four patients had disease progression by RECIST but were reaping clinical benefits and allowed to remain on study. The remaining patients discontinued vandetanib because of adverse events $(n=7)$, disease progression $(n=4)$, or withdrawal of consent $(n=2)$. The majority of patients had MEN 2A disease, and 29 of the 30 had evidence of metastatic disease at presentation. Twenty percent of subjects $(n=6)$ achieved a partial response, and another 53\% had stable disease for more than 24 weeks. The median duration of response was 10.2 (range 1.9-16.9) months, confidence interval (CI) 8.0-13.2 months. The majority of patients $(80 \%)$ had reductions in calcitonin levels to less than half their baseline values for at least 4 weeks. ${ }^{22}$

The second of the two Phase II trials had similar eligibility criteria. However, in this study, a lower dose of the drug (100 mg) was chosen as monotherapy in patients with locally advanced or metastatic familial forms of MTC. The primary objective again was to assess the objective response rate with vandetanib, according to RECIST criteria. In this study, if disease progression was noted on imaging, a post-progression treatment phase was allowed. If the investigator believed that there may have been clinical benefit from therapy, then patients could enter post-progression treatment with vandetanib at a higher dose of $300 \mathrm{mg} /$ day until objective disease progression occurred at this dose, or until another withdrawal criterion was met. Nineteen patients were recruited between August 2006 and May 2007; initially, all received 100 mg daily. At the time of data cutoff, 11 were continuing on this dose, and the remaining patients had discontinued initial treatment. Four of these patients had disease progression, and all entered post-progression treatment with vandetanib $300 \mathrm{mg}$ daily. There were no complete responses; three (16\%) were partial responders, and 10 patients had stable disease for 24 weeks or longer. In this study, disease control was seen in $68 \%$ of all patients (including complete and partial responders and those who had stable disease for longer than 24 weeks). Toxicities were manageable in both trials, with the most common adverse events being diarrhea, rash, and asymptomatic QTc prolongation on electrocardiogram. Seven patients in the trial using $300 \mathrm{mg}$ discontinued treatment because of adverse events, five of which were felt by the investigator to be related to vandetanib (acne, hemorrhagic diarrhea, QTc prolongation, abnormal renal function, and nausea). ${ }^{23}$ Although it could be seen from both trials that $100 \mathrm{mg}$ and $300 \mathrm{mg}$ daily of vandetanib had activity in this disease, no direct comparison of these dose levels has been conducted. The level chosen for the randomized placebo-controlled study was $300 \mathrm{mg}$ daily.

\section{Phase II/III randomized placebo-controlled trial}

The encouraging results of these single-arm trials spurred accrual onto an international randomized Phase II/III trial known as ZETA (Zactima Efficacy Study versus Tarceva) comparing ZD6474 (vandetanib) and placebo in patients with inherited and sporadic forms of MTC. ${ }^{24}$ In this large trial, 331 adults with unresectable locally advanced or metastatic MTC were randomized in a 2:1 manner to receive either ZD6474 at a dose of $300 \mathrm{mg}$ daily, or placebo. Between December 2006 and November 2007, 231 subjects were assigned to vandetanib and 100 received placebo. The majority of patients had sporadic disease $(90 \%)$, metastatic disease (95\%), and tumors that were positive for a RET mutation (56\%). Patients were followed until disease progression, at which time they were unblinded and had the option to receive vandetanib in an open-label trial; if they chose open-label 
vandetanib, they were then followed for survival. The median duration of treatment was 90.1 weeks in the vandetanib arm and 39.9 weeks in the placebo arm. The primary objective of the ZETA study was demonstration of improvement in progression-free survival on vandetanib compared with placebo. Other endpoints included evaluation of overall survival and objective response rate.

Two-year follow-up results showed that $37 \%$ of the patients had progression, and $15 \%$ had died. The primary endpoint of the study, ie, progression-free survival, was met, with the researchers reporting a hazards ratio (HR) of 0.46 (95\% CI: $0.31-0.69)$. The median progression-free survival was 19.3 months in the placebo group, and had not yet been reached in the vandetanib arm at the time of data presentation at the 14th International Thyroid Congress in 2010. A significant improvement in progression-free survival was observed for patients randomized to receive vandetanib (HR: 0.35 , 95\% CI: $0.24-0.53 ; P<0.0001$ ). While the progression-free survival data led to United States Food and Drug Administration (FDA) approval, no significant overall survival difference was noted in the two arms because of the crossover design of the study.

Vandetanib was also associated with statistically significant advantages in the secondary endpoints, such as objective response rate (45\% vs $13 \%$; odds ratio [OR]: 5.4); disease control rate of 24 weeks or more (OR: 2.64); calcitonin biochemical response (OR: 72.9); carcinoembryonic antigen biochemical response (OR: 52); and time to worsening of pain (HR: 0.61). Some of the radiological responses were dramatic. At this time, it is not known whether any biochemical, radiological, or clinical parameters significantly predict response. Data are also not yet available on whether certain metastatic sites respond better than others. In the placebo arm, 12 of 13 responses occurred after the patients had received open-label vandetanib. Adverse events were more common with vandetanib than on placebo, including diarrhea $(56 \%$ vs $26 \%$ ), rash ( $45 \%$ vs $11 \%$ ), nausea ( $33 \%$ vs $16 \%$ ), hypertension ( $32 \%$ vs $5 \%$ ), and headache ( $26 \%$ vs $9 \%$ ). The most severe toxicities were QT prolongation, torsades de pointes, and sudden death, which are addressed in a boxed warning in the prescribing information.

Based on these results, Astra Zeneca filed for FDA approval of the drug in the US and the European Medicines Agency in Europe late in 2010, receiving an orphan drug designation by the FDA on December 2, 2010, with final approval granted on April 6, 2011. ${ }^{25}$ The approval was specifically for patients who are ineligible for surgery and have disease that is growing or causing symptoms. The benefits of the drug in patients who have occult or micrometastatic disease but with a rapid calcitonin doubling time are not known.

The severe cardiac side effects mentioned previously are addressed in a boxed warning in the prescribing information. Vandetanib has a prolonged half-life of 19 days, so electrocardiograms and levels of serum potassium, calcium, magnesium, and thyroid-stimulating hormone are recommended to be obtained at baseline, at 2-4 weeks, and at 8-12 weeks after starting treatment, and every 3 months thereafter as long as the patient remains on treatment. As a result of the FDA concern about toxicity, only US prescribers and pharmacies certified through the Vandetanib Risk Evaluation Mitigation Strategy (REMS) program, ie, a restricted distribution program, are able to prescribe and dispense vandetanib.

\section{Clinical utility of vandetanib in the treatment of MTC}

Vandetanib became the first systemic agent to be approved for the treatment of locally advanced or metastatic MTC. Therefore, it represents a new standard of care for these patients. However, MTC can be an indolent disease, and subsequent studies have demanded that patients have radiographic progression of disease prior to enrollment, such as the randomized Phase III study of XL-184. Some patients may have a symptom-free existence for many years on observation alone, and therefore are unlikely to gain much benefit from the addition of a systemic agent. The potentially serious cardiac side effects call for caution in prescribing this medication to otherwise asymptomatic individuals. The less serious but quality-of-life altering effects, such as acneiform rash and nausea, also deter some patients and physicians from starting the drug immediately on signs of biochemical progression of disease. The high cost of a new tyrosine kinase inhibitor is also likely to limit the number of patients who may have access to this medication. However, some patients could gain significant benefit; these include those with clear radiographic progression or significant symptoms related to their disease, those who have no or limited cardiac histories, and those who are reliable enough to comply with close follow-up. By closely monitoring of electrolyte levels and electrocardiograms, the authors have found it possible to avoid any cardiac events in their patient population to date.

Resistance may also arise in tumors exposed to vandetanib. The authors speculate that there may be many reasons for this, including new molecular abnormalities involving RET or other receptors, such as loss of expression, genomic 
amplification, or the activation of alternative downstream signaling pathways. Further work needs to be done to elucidate which of these is most important. The combination of vandetanib and other drugs may help delay or overcome some resistance mechanisms. Many such drugs have been evaluated in MTC and other forms of thyroid cancer with varying degrees of success. ${ }^{26-35}$

\section{Conclusion}

Vandetanib has emerged as an effective targeted therapy in the treatment of MTC. Its recent FDA approval for patients with metastatic or unresectable disease is a landmark in the history of this condition. Its development as a targeted agent and the results of Phase II and randomized studies have become a proof of principle. Future studies involving combinations with other systemic agents are eagerly awaited and may further improve upon the significant results seen to date with this agent.

\section{Disclosure}

HAD sits on the advisory board for Astra Zeneca (mock Oncologic Drugs Advisory Committee meeting).

\section{References}

1. Carling T, Udelsman R. Thyroid tumors. In: DeVita VT, Hellman S, Rosenberg SA, editors. Cancer: Principles and Practice of Oncology. Philadelphia, PA: Lippincott Williams \& Wilkins; 2011.

2. Hazard JB, Hawk WA, Crile G Jr. Medullary (solid) carcinoma of the thyroid; a clinicopathologic entity. J Clin Endocrinol Metab. 1959; 19(1):152-161.

3. Friedell GH, Carey RJ, Rosen H. Familial thyroid cancer. Cancer. 1962; 15:241-245.

4. Sipple JH. The association of pheochromocytoma with carcinoma of the thyroid gland. Am J Med. 1961;31(1):163-166.

5. Steiner AL, Goodman AD, Powers SR. Study of a kindred with pheochromocytoma, medullary thyroid carcinoma, hyperparathyroidism and Cushing's disease: multiple endocrine neoplasia, type 2. Medicine (Baltimore). 1968;47(5):371-409.

6. Sakorafas GH, Friess H, Peros G. The genetic basis of hereditary medullary thyroid cancer: clinical implications for the surgeon, with a particular emphasis on the role of prophylactic thyroidectomy. Endocr Relat Cancer. 2008;15(4):871-884.

7. B Brandi ML, Gagel RF, Angeli A, et al. Guidelines for diagnosis and therapy of MEN type 1 and type 2. J Clin Endocrinol Metab. 2001; 86(12):5658-5671.

8. Dottorini ME, Assi A, Sironi M, Sangalli G, Spreafico G, Colombo L. Multivariate analysis of patients with medullary thyroid carcinoma. Prognostic significance and impact on treatment of clinical and pathologic variables. Cancer. 1996;77(8):1556-1565.

9. Roman S, Lin R, Sosa JA. Prognosis of medullary thyroid carcinoma: demographic, clinical, and pathologic predictors of survival in 1252 cases. Cancer. 2006;107(9):2134-2142.

10. Scherubl H, Raue F, Ziegler R. Combination chemotherapy of advanced medullary and differentiated thyroid cancer. Phase II study. $J$ Cancer Res Clin Oncol. 1990;116(1):21-23.

11. Deshpande HA, Gettinger SN, Sosa JA. Novel chemotherapy options for advanced thyroid tumors: small molecules offer great hope. Curr Opin Oncol. 2008;20(1):19-24.
12. Schimke RN, Hartmann WH. Familial amyloid-producing medullary thyroid carcinoma and pheochromocytoma. A distinct genetic entity. Ann Intern Med. 1965;63(6):1027-1039.

13. Takahashi M, Ritz J, Cooper GM. Activation of a novel human transforming gene, RET, by DNA rearrangement. Cell. 1985;42(2):581-588.

14. Eng C. RET protooncogene in the development of human cancer. J Clin Oncol. 1999;17(1):380-393.

15. Capp C, Wajner SM, Siqueira DR, Brasil BA, Meurer L, Maia AL. Increased expression of vascular endothelial growth factor and its receptors, VEGFR-1 and VEGFR-2, in medullary thyroid carcinoma. Thyroid. 2010;20(8):863-871.

16. Ferrara N, Gerber HP, LeCouter J. The biology of VEGF and its receptors. Nat Med. 2003;9(6):669-676.

17. Wedge SR, Ogilvie DJ, Dukes M, et al. ZD6474 inhibits vascular endothelial growth factor signaling, angiogenesis, and tumor growth following oral administration. Cancer Res. 2002;62(16): $4645-4655$.

18. Carlomagno F, Vitagliano D, Guida T, et al. ZD6474, an orally available inhibitor of KDR tyrosine kinase activity, efficiently blocks oncogenic RET kinases. Cancer Res. 2002;62(24):7284-7290.

19. Herbst RS, Heymach JV, O'Reilly MS, Onn A, Ryan AJ. Vandetanib (ZD6474): an orally available receptor tyrosine kinase inhibitor that selectively targets pathways critical for tumor growth and angiogenesis. Expert Opin Investig Drugs. 2007;16(2):239-249.

20. Holden SN, Eckhardt SG, Basser R, et al. Clinical evaluation of ZD6474, an orally active inhibitor of VEGF and EGF receptor signaling, in patients with solid, malignant tumors. Ann Oncol. 2005;16(8):1391-1397.

21. Tamura T, Minami H, Yamada Y, et al. A phase I dose-escalation study of ZD6474 in Japanese patients with solid, malignant tumors. JThorac Oncol. 2006;1(9):1002-1009.

22. Wells SA Jr, Gosnell JE, Gagel RF, et al. Vandetanib for the treatment of patients with locally advanced or metastatic hereditary medullary thyroid cancer. J Clin Oncol. 2010;28(5):767-772.

23. Robinson BG, Paz-Ares L, Krebs A, Vasselli J, Haddad R. Vandetanib $(100 \mathrm{mg})$ in patients with locally advanced or metastatic hereditary medullary thyroid cancer. J Clin Endocrinol Metab. 2010;95(6): 2664-2671.

24. Wells SA, Robinson BG, Gagel RF, et al. Vandetanib in locally advanced or metastatic medullary thyroid cancer: a randomized double blind Phase III trial (ZETA) [abstract]. J Clin Oncol. 2010;28(15 Suppl): Abst 5503.

25. Vandetanib (ZD6474) tablets Oncologic Drugs Advisory Committee (ODAC) Meeting Briefing Document 02 December 2010. Available at: http://www.fda.gov/downloads/AdvisoryCommittees/Commit teesMeetingMaterials/Drugs/OncologicDrugsAdvisoryCommittee/ UCM235092.pdf. Accessed October 31, 2011.

26. Ahuja S, Ernst H. Chemotherapy of thyroid carcinoma. J Endocrinol Invest. 1987;10(3):303-310.

27. Matuszczyk A, Petersenn S, Voigt W, et al. Chemotherapy with paclitaxel and gemcitabine in progressive medullary and thyroid carcinoma of the follicular epithelium. Horm Metab Res. 2010;42(1):61-64.

28. Gilliam LK, Kohn AD, Lalani T, et al. Capecitabine therapy for refractory metastatic thyroid carcinoma: a case series. Thyroid. 2006;16(8): 801-810.

29. Kurzrock R, Cohen EE, Sherman SI, et al. Long-term results in a cohort of medullary thyroid cancer (MTC) patients (pts) in a phase I study of XL184 (BMS 907351), an oral inhibitor of MET, VEGFR2, and RET [abstract]. J Clin Oncol. 2010;28(15 Suppl):Abst 5502.

30. Salgia R, Sherman S, Hong DS, et al. A phase I study of XL184, a MET, VEGFR2, and RET kinase inhibitor, administered orally to patients (pts) with advanced malignancies including a subgroup of patients with medullary thyroid cancer (MTC) [abstract]. J Clin Oncol. 2008; 26 Suppl:Abst 3522.

31. Schlumberger MJ, Elisei R, Bastholt L, et al. Phase II study of safety and efficacy of motesanib in patients with progressive or symptomatic, advanced or metastatic medullary thyroid cancer. J Clin Oncol. 2009; 27(23):3794-3801. 
32. Deshpande HA, Gettinger S, Sosa JA. Axitinib: The evidence of its potential in the treatment of advanced thyroid cancer. Core Evid. 2010;4:43-48.

33. Cohen EE, Rosen LS, Vokes EE, et al. Axitinib is an active treatment for all histologic subtypes of advanced thyroid cancer: results from a phase II study. J Clin Oncol. 2008;26(29):4708-4713.

34. Lam ET, Ringel MD, Kloos RT, et al. Phase II clinical trial of sorafenib in metastatic medullary thyroid cancer. J Clin Oncol. 2010;28(14): 2323-2330.
35. Carr LL, Mankoff DA, Goulart BH, et al. Phase II study of daily sunitinib in FDG-PET-positive, iodine-refractory differentiated thyroid cancer and metastatic medullary carcinoma of the thyroid with functional imaging correlation. Clin Cancer Res. 2010;16(21): 5260-5268.

\section{Publish your work in this journal}

OncoTargets and Therapy is an international, peer-reviewed, open access journal focusing on the pathological basis of all cancers, potential targets for therapy and treatment protocols employed to improve the management of cancer patients. The journal also focuses on the impact of management programs and new therapeutic agents and protocols on

\section{Dovepress}

patient perspectives such as quality of life, adherence and satisfaction The manuscript management system is completely online and includes a very quick and fair peer-review system, which is all easy to use. Visit http://www.dovepress.com/testimonials.php to read real quotes from published authors.

Submit your manuscript here: http://www.dovepress.com/oncotargets-and-therapy-journal 